\title{
DIGITAL TECHNOLOGIES AS A FACTOR IN REDUCING CORRUPTION IN THE JUDICIAL SYSTEM ${ }^{1}$
}

\author{
Olga I. Miroshnichenko \\ Far Eastern Federal University, Vladivostok, Russian Federation; \\ Peoples' Friendship University of Russia, Moscow, Russian Federation \\ Tatyana V. Filonenko \\ Primorsky Krai Prosecutor's Office, Vladivostok, Russian Federation; \\ Far Eastern Federal University, Vladivostok, Russian Federation
}

\begin{abstract}
Introduction: the authors discuss the topic of digitalization as potentially one of the most effective ways to fight against corruption in modern Russia. Various forms of information technology application are analyzed, including "egovernment", "e-Parliament", and "e-justice". Pointing to the certainly positive side of this phenomenon, such as the impossibility of the use of private agreements in the decision-making process in favor of one side or another, etc., the authors note the shortcomings of the procedure of digitalization, such as, for example, the ability of a human judge to "let all the circumstances of the incident go through himself", to very humanely evaluate the motives of the crime, the attitude of the perpetrator towards the offense, the possibility of socializing the specified person; and on this basis to determine a fair and reasonable form and amount of punishment. The purpose of the research: to reveal the importance of introducing modern information technologies in the work of all branches of government as one of the areas of anticorruption. Objectives: to reveal the content of the term "e-justice", to consider the main trends in the research on the issues related to the proliferation of digital technologies in the administration of justice and to assess the adequacy of their magnitude to modern realities; to emphasize the question of practical implementation of information technology as an effective mechanism of the fight against corruption. Methods: system, structural and functional, analysis, synthesis, expert assessment. Results: the authors describe one of the trends of the modern interdisciplinary research, which is not sufficiently covered in the scientific literature, and is manifested in an attempt to see the novelty in the relations through the use of the latest technical means; the activities carried out in electronic form and/or through the use of digital technologies, dedicated to the digitalization of the judicial system, aimed at improving the quality of the work of the courts, ensuring maximum transparency of their decision-making and reducing corruption in the justice system. Conclusions: the digitalization of cases will reduce all document flow and ensure the safety of all available criminal cases and materials, allowing us to improve the quality of preliminary investigation or preparation for trials, reduce the risks of possible falsification of evidence, and the introduction of "electronic justice" will reduce the manifestation of any forms of corruption in the justice sector.

ते Key words: digitalization, information technologies, e-government, e-justice, corruption.

Cit Citation. Miroshnichenko O.I., Filonenko T.V. Digital Technologies as a Factor in Reducing Corruption in the Judicial System. Legal Concept, 2020, vol. 19, no. 2, pp. 136-143. (in Russian). DOI: https://doi.org/10.15688/ lc.jvolsu.2020.2.20

\section{ЦИФРОВЫЕ ТЕХНОЛОГИИ КАК ФАКТОР СНИЖЕНИЯ КОРРУПЦИОННЫХ ПРОЯВЛЕНИЙ В СУДЕБНОЙ СИСТЕМЕ ${ }^{1}$}

\author{
Ольга Игоревна Мирошниченко
}

Дальневосточный федеральный университет, г. Владивосток, Российская Федерация; Российский университет дружбы народов, г. Москва, Российская Федерация 


\section{Татьяна Викторовна Филоненко}

Прокуратура Приморского края, г. Владивосток, Российская Федерация; Дальневосточный федеральный университет, г. Владивосток, Российская Федерация

Введение: авторы рассуждают на тему цифровизации как потенциально одного из эффективных способов борьбы с коррупцией в современной России. Анализируются различные формы применения информационных технологий, в том числе «электронное правительство», «электронный парламент», «электронное правосудие». Указывая на несомненно положительные стороны данного явления, такие как невозможность использования личных договоренностей в процессе принятия решений в пользу той или иной стороны и т. д., авторы отмечают и недостатки процессуальной цифровизации, такие как, например, способность человека-судьи «пропустить через себя» все обстоятельства произошедшего, именно по-человечески оценить мотивы совершенного преступления, отношение преступника к содеянному, возможность социализации указанного лица, и уже на основе этого определить справедливый и разумный вид и размер наказания. Цель исследования: раскрыть значение внедрения современных информационных технологий в работу всех ветвей государственной власти как одного из направлений противодействия коррупции. Задачи: раскрыть наполнение термина «электронное правосудие», рассмотреть основные тенденции исследований по вопросам, связанным с распространением цифровых технологий при отправлении правосудия и оценить адекватность масштаба их распространения современным реалиям; обозначить вопрос внедрения цифровых технологий как эффективного механизма противодействия коррупции. Методы: системный, структурно-функциональный, анализ, синтез, экспертная оценка. Результаты: описывается одна из тенденций современных междисциплинарных исследований, недостаточно освещаемая в научной литературе, которая проявляется в попытке увидеть новизну в отношениях с использованием новейших технических средств; отношениях, осуществляемых в электронной форме и/или с применением цифровых технологий, посвященная переходу работы судебной системы на цифровые технологии, имеющая целью повышение качества работы судов, обеспечение максимальной прозрачности принятия ими решений и снижение коррупционных проявлений в системе правосудия. Выводы: переход на электронную форму дел позволит сократить весь документооборот и обеспечит сохранность всех имеющихся уголовных дел и материалов, позволяя улучшить качество предварительного расследования или подготовки к судебному заседанию, снизить риски возможной фальсификации доказательств, а внедрение «электронного правосудия» приведет к сокращению проявления любых форм коррупции в сфере правосудия.

Ключевые слова: цифровизация, информационные технологии, электронное правительство, электронное правосудие, коррупция.

Цитирование. Мирошниченко О. И., Филоненко Т. В. Цифровые технологии как фактор снижения коррупционных проявлений в судебной системе // Legal Concept = Правовая парадигма. -2020 . - T. 19, № 2. C. 136-143. -DOI: https://doi.org/10.15688/lc.jvolsu.2020.2.20

\section{Введение}

Проблема коррупции была и остается одной из самых актуальных в современной России, поскольку является серьезным препятствием на пути развития страны, формирования гражданского общества [10].

Коррупция как явление оказывает разрушительное воздействие на все правовые институты, в результате чего закрепленные в законодательстве нормы права заменяются вариантами разрешения любых ситуаций, в интересах конкретных лиц. Серьезная угроза кроется как во вторжении коррупции в систему юстиции в целом, так и отправления правосудия в частности, поскольку это с неизбежностью приведет к деформированию общей практики правоприменения, а также сделает ее менее цивилизованной и эффективной [5, с. 23].
Несмотря на то что в последние годы способы и механизмы борьбы с коррупционными проявлениями претерпели значительные изменения, как и уголовное законодательство, направленное на борьбу с преступлениями данной категории, вопросы противодействия коррупции криминологическими, а также иными средствами остаются по-прежнему актуальными. Представляется, что вопросы эффективной комплексной борьбы с коррупцией в государстве по-прежнему остаются нерешенными.

\section{К вопросу об актуальности исследования}

Актуальность исследования вопросов противодействия коррупции в судебной системе подтверждается тем, что конфликт ин- 
тересов на государственной службе является одной из самых острых проблем российской действительности. Как следствие, результаты опроса населения сотрудниками Независимого исследовательского центра свидетельствуют о том, что только каждый второй россиянин доверяет органам судебной власти, а в качестве основной причины недоверия названа коррупция (44 \%) [7].

Очевидно, поэтому в своем ежегодном Послании Федеральному собранию в 2018 г. В.В. Путин призвал продолжать бороться с коррупцией. При этом он подчеркнул, что вся система государственной службы должна быть перестроена исходя из принципов эффективности и нацеленности на результат. По его словам, в течение шести лет практически все государственные услуги необходимо перевести в режим реального времени с использованием дистанционных сервисов, а документооборот между государственными структурами - в цифровую форму. Президент высказал мнение о том, что именно цифровизация бюрократической работы позволит повысить прозрачность деятельности сотрудников государственной службы, а также выступит реальным механизмом в противодействии коррупции [8].

\section{Цифровые технологии в сфере правосудия}

В настоящее время в современной России одним из направлений противодействия коррупционным проявлениям является внедрение современных цифровых технологий в работу органов государственной власти [2].

Использование информационных технологий объединяется термином «электронное государство», что, в свою очередь, включает такие понятия, как «электронное правительство», «электронный парламент», «электронное правосудие».

Под электронным правосудием понимается такой способ отправления правосудия, который основан на использовании технических систем с цифровой обработкой данных [6].

Федеральный закон «Об обеспечении доступа к информации о деятельности судов в Российской Федерации» закрепил основные принципы, такие как:
- открытость и доступность информации о деятельности судов;

- достоверность информации об их деятельности;

- соблюдение прав граждан на неприкосновенность частной жизни, личную и семейную тайну, защиту их чести и деловой репутации, права организаций на защиту их деловой репутации и др. [12].

Эксперты, проводящие анкетирование действующих судей и их помощников по вопросам влияния электронного правосудия на снижение коррупции в судебной системе, задали судьям и аппарату суда вопрос: «Как вы считаете, является ли внедрение электронного правосудия одним из направлений борьбы с коррупцией политики государства»? При этом три четверти (70 \%) опрошенных ответили на него утвердительно [9].

На сегодняшний момент лидером в работе по внедрению электронного правосудия стала система арбитражных судов Российской Федерации, на примере работы которой лучше всего заметны возможности электронного правосудия, влияние цифровых технологий на работу системы в целом, а также перспективы ее развития [1].

На данный момент в работе системы доступны три актуальные функции. Во-первых, это возможность подать иск или жалобу в электронном виде. Во-вторых, стороны также могут воспользоваться правом на получение судебных решений в электронной форме. В-третьих, у сторон есть возможность следить за движением дела, просматривать электронные документы по делу и т. д.

Рассмотрим более детально элементы электронного правосудия. Эксперты выделяют в нем условно несколько групп:

- организация работы внутри суда. В настоящее время действует ряд информационных систем, которые автоматизируют и оптимизируют работу суда. Так, в судах общей юрисдикции активно используется государственная автоматизированная система «Правосудие», имеющая многоуровневую иерархическую структуру и включающая в себя ряд подсистем по работе с кадрами, судебным делопроизводством, статистикой и т. д.;

- взаимодействие между судами и другими органами. В судебной системе активно 
внедряются технологии взаимодействия как между судами, так и между судами и другими организациями. В качестве положительного примера можно привести Республику Татарстан, в которой успешно используется в настоящее время портал «Электронный Татарстан». Система позволяет заявителю в сжатые сроки получать всю необходимую информацию. В данную систему включены органы внутренних дел, органы, исполняющие наказания, Служба судебных приставов, суды и др. [14];

- автоматическое распределение дел также является еще одним новым немаловажным элементом электронного правосудия, направленным на обеспечение деятельности судов.

Такой механизм распределения дел запущен во многих субъектах РФ и зарекомендовал себя с положительной стороны. Так, в Липецкой области модуль «Автоматическое распределение дел» в экспериментальном порядке начал свою работу с 2011 г. в трех судах области. В Краснодарском крае использование модуля распределения дел началось в Первомайском районном суде г. Краснодара еще в 2009 году. В Московском районном суде г. Казани модуль «Автоматическое распределение дел» заработал с 2012 года [14]. И все же говорить о повсеместном введении автоматического распределения дел пока рано. Стоит согласиться с Р.А. Шарифуллиным в том, что данный механизм распределения дел будет способствовать обеспечению прозрачности и незаинтересованности судьи в случае принятия окончательного решения. Кроме этого, необходимо отметить, что автоматическое распределение дел позволит в дальнейшем справедливо распределить нагрузку среди судей, а также оперативно выполнять задачи системы правосудия.

Стоит отметить, что в уголовном судопроизводстве термин «электронное правосудие» пока не используется. При этом в УПК РФ предусмотрены отдельные способы совершения процессуальных действий в электронном виде. Например, закреплено понятие «электронный носитель информации». В соответствии с п. 5 ч. 2 ст. 82 УПК РФ вещественные доказательства, в том числе и те, которые содержатся на электронных носителях, хранятся в опечатанном виде в условиях, ис- ключающих возможность доступа к ним посторонних лиц, возвращаются их законному владельцу после производства всех необходимых следственных действий.

Важной мерой, связанной с внедрением информационных технологий в уголовный процесс, стало принятие Федерального закона от 23.06.2016 № 220-Ф3 «О внесении изменений в отдельные законодательные акты Российской Федерации в части применения электронных документов в деятельности органов судебной власти», которым в Уголовно-процессуальный кодекс РФ введена ст. 474.1 «Порядок использования электронных документов в уголовном судопроизводстве». Эта норма предусматривает подачу в суд отдельных процессуальных документов (ходатайство, заявление, жалоба, представление и прилагаемые к ним материалы) в форме электронного документа, заверенного электронной подписью. В такой же форме допускается изготавливать судебные решения (за исключением случаев, указанных в ч. 2 ст. 474.1 УПК РФ), направлять их копии участникам уголовного судопроизводства (для этого необходимы их просьба или согласие) с использованием Интернета (ч. 3 ст. 474.1 УПК РФ). Таким образом, создаются реальные условия для внедрения электронного документооборота в уголовном судопроизводстве, что позволит отказаться от бумажных процессуальных документов и перейти на электронную форму уголовного дела, которая в значительной мере упростит процедуры собирания доказательств и составления процессуальных документов [11].

В настоящее время для реализации идеи внедрения электронной формы уголовного дела существенное значение имеет успешная реализация Федеральной целевой программы «Развитие судебной системы России на 20132020 годы».

При этом самой важной новеллой указанной федеральной целевой программы является создание пилотного проекта «Электронное дело», суть которого заключается в организации входного сканирования всех поступающих в суды документов и формировании электронных дел. Очевидно, что электронная форма дела планируется к применению как в арбитражных судах, так и, возможно, в судах общей юрисдикции, в том 
числе при рассмотрении и разрешении уголовных дел.

Обсуждая вопрос внедрения цифровых технологий как эффективного механизма противодействия коррупции, нельзя не коснуться разработанной системы «Электронные весы правосудия», представленной Х.Д. Аликперовым. Суть разработанной программы заключается в том, что она позволяет помочь профессиональному судье определить оптимальный вид и размер санкции для конкретного подсудимого. Значимые для определения наказания характеристики личности обвиняемых представляются в виде файла, в котором отражены все отягчающие и смягчающие вину обстоятельства. Программой выработан также механизм определения оптимального вида и размера наказания. При этом за судьей сохраняется право принятия окончательного решения. Презентация указанной программы породила дискуссию в экспертных кругах на предмет ее эффективности [3]. Позволим и мы себе высказаться на этот счет.

Предложенная программа, безусловно, ориентирована на снижение коррупционных проявлений в системе правосудия, а также формирование большего доверия к судейскому корпусу. В условиях перехода работы судебной системы на цифровые технологии, которые призваны повысить качество работы судов, а также обеспечить максимальную прозрачность при принятии ими решений, представленная программа, безусловно, заслуживает уважения. Вместе с тем, если взглянуть на ее реализацию с практической стороны, возникает ряд важных вопросов. Стоит согласиться с Н.А. Крайновой в том, что, назначая наказание, судья должен иметь в виду ресоциализирующее значение его вида и размера. Немаловажную роль в реализации функции наказания играет отношение осужденного к назначенному ему наказанию, восприятие санкции как справедливой и соразмерной содеянному. Можно много говорить о «качестве» судейского корпуса, коррупционной составляющей и в этой связи делать вывод о том, что «машина» справится с расчетом вида и размера наказания лучше, но хочется обратить внимание на существование таких понятий, как гуманность, человечность, которые вряд ли могут быть в должной мере применены к ин- формационным программам [4, с. 35-37]. К тому же, никто кроме судьи, рассматривающего дело и «пропускающего через себя» все обстоятельства произошедшего, не сможет лучше оценить мотивы совершенного преступления, отношение преступника к содеянному, возможность социализации указанного лица, а главное - определить справедливый и разумный вид и размер наказания. Представляется сомнительным, что машина сможет заменить человека именно на данном ключевом этапе принятия решения. Ведь, по сути, приговор (вид и размер наказания в том числе) является кульминацией рассмотрения уголовного дела, и замена профессионального судьи машиной приведет к утрате юридических навыков профессионалов, которые будут искусственно загнаны в рамки, определяемые программой, понижению авторитета судебной власти. Не оспаривая того обстоятельства, что переход на цифровые технологии в судебной системе неизбежен, нам все же представляется, что ключевые компетенции, как минимум в уголовном процессе, должны оставаться в руках профессионалов, а подобные программы - рассматриваться представителями судейского корпуса лишь в качестве рекомендованной альтернативы.

\section{Выводы}

Подводя некоторые итоги, хочется отметить, что в целом переход на электронную форму дел не только сократит документооборот и обеспечит сохранность материалов, но и позволит улучшить качество предварительного расследования или подготовки к судебному заседанию, снизить риски возможной фальсификации доказательств.

Внедрение «электронного правосудия», по нашему мнению, способно резко сократить проявления любых форм коррупции в сфере правосудия, поскольку физические и юридические лица будут лишены возможности лично контактировать с сотрудниками государственных учреждений, что, в свою очередь, автоматически означает невозможность использования личных договоренностей в процессе принятия решений в пользу той или иной стороны. При этом стороны смогут в любое время и из любой точки мира получать необ- 
ходимые данные в рамках конкретного дела, а отправление правосудия станет максимально прозрачным.

Исходя из изложенного, полагаем, что внедрение электронного правосудия на всех уровнях судебной системы может стать еще одним эффективным механизмом, направленным на минимизацию коррупционных проявлений в указанной сфере.

\section{ПРИМЕЧАНИЕ}

${ }^{1}$ Исследование выполнено при финансовой поддержке гранта Президента РФ № НШ-2668-2020.6 «Национально-культурные и цифровые тренды социально-экономического и политико-правового развития Российской Федерации в XXI веке».

This work was financially supported by the Grant of the President of the Russian Federation No. HШ-2668-2020.6 "National-Cultural and Digital Trends in the Socio-Economic, Political and Legal Development of the Russian Federation in the $21^{\text {st }}$ Century".

\section{СПИСОК ЛИТЕРАТУРЫ}

1. Информационная безопасность России в цифровой экономике: экономические и правовые аспекты / Е. Е. Фролова [и др.] // Journal of advanced research in law and economics. - 2018. - T. 9, № 1. C. 89-95.

2. Иншакова, А. О. Цифровые технологии альтернативных методов разрешения споров: зарубежная практика и перспективы применения в России / А. О. Иншакова, Ю. А. Тымчук // Право и управление. XXI век. - 2018. - № 1 (46). - С. 23-31.

3. Криминология: вчера, сегодня, завтра. 2019. - № 1 (52). - С. 18-57. - Электрон. текстовые дан. - Режим доступа: https:/www.elibrary.ru/ contents.asp?id=38201690 (дата обращения: 02.04.2020). - Загл. с экрана.

4. Крайнова, Н. А. Электронные весы правосудия: цифровизация процессов или оцифровка задач? / Н. А. Крайнова // Криминология: вчера, сегодня, завтра. - 2019. - № 1 (52). - С. 35-38.

5. Кузьмин, Н. А. К вопросу о понятии и природе коррупции / Н. А. Кузьмин // Российский следователь. - 2009. - № 24. - С. 23-26.

6. Носков, И. Ю. Внедрение электронного правосудия как важнейшее направление совершенствования судебной системы Российской Федерации / И. Ю. Носков // Современное право. - 2011.№ 10. - С. 120-122.
7. Отношение россиян к судебной системе (итоги всероссийского опроса) // АНО «Независимый исследовательский центр» : офиц. сайт. - Электрон. текстовые дан. - Режим доступа: http://исследовательский-центр.pф/otnoshenie-rossiyan-ksudebnoj-sisteme-itogi-vserossijskogo-oprosa/ ?ckattempt=1 (дата обращения: 04.05.2018). - Загл. с экрана.

8. Послание Президента РФ Федеральному Собранию от 01.03.2018 // Российская газета. - 2018. 2 марта. - Электрон. текстовые дан. - Режим доступа: https://rg.profkiosk.ru/default?mid=30442. - Загл. с экрана.

9. Селиванова, В. Д. Электронное правосудие как фактор снижения коррупции в органах судебной власти / В. Д. Селиванова // Служебные преступления: вопросы теории и практики правоприменения : сб. материалов Междунар. науч.-практ. конф. (17 мая 2018 г., г. Хабаровск) / Ф. М. Абубакиров, В. В. Агильдин, Е. Ю. Антонова [и др.] ; под ред. Т. Б. Басовой, К. А. Волкова ; Хабаровский краевой суд, Российское объединение судей в Хабаровском крае, Дальневосточный филиал Российской академии правосудия. - Хабаровск : Юрист, 2018. - $132 \mathrm{c}$.

10. Суходолов, А. П. Введение в основы системной антикоррупционной профилактики / А. П. Суходолов [и др.] // Криминологический журнал Байкальского государственного университета экономики и права. - 2016. - Т. 10, № 1. - С. 5-19. - DOI: 10.17150/1996-7756.2016.10(1).5-19.

11. Уголовно-юрисдикционная деятельность в условиях цифровизации : монография / Н. А. Голованова, А. А. Гравина, О. А. Зайцев [и др.]. - М. : ИЗиСП : КОНТРАКТ, 2019. - 212 с.

12. Федеральный закон от 22 декабря 2008 г. № 262-Ф3 «Об обеспечении доступа к информации о деятельности судов в Российской Федерации» (в ред. от 23.06.2016) // Собрание законодательства РФ. - 2008. - № 52 (ч. 1). - С. 6217.

13. Федеральный закон от 14.06.2011 № 140-Ф3 «О внесении изменений в статью 14 Гражданского процессуального кодекса Российской Федерации и статью 30 Уголовно-процессуального кодекса Российской Федерации» // Российская газета. - 2011. № 129. - С. 4-5.

14. Шарифуллин, Р. А. Элементы электронного правосудия / Р. А. Шарифуллин, Р. С. Бурганов, Р. Г. Бикмиев // Российский судья. - 2018. - № 6. C. 57-62.

\section{REFERENCES}

1. Frolova E.E., Polyakova T.A., Dudin M.N., Rusakova E.P., Kucherenko P.A. Informatsionnaya 
bezopasnost Rossii v tsifrovoy ekonomike: ekonomicheskiye i pravovyye aspekty [Information Security of Russia in the Digital Economy: The Economicand Legal Aspects]. Journal of Advanced Research in Law and Economics, 2018, vol. 9, no. 1, pp. 89-95.

2. Inshakova A.O., Tymchuk Yu.A. Tsifrovyye tekhnologii alternativnykh metodov razresheniya sporov: zarubezhnaya praktika i perspektivy primeneniya v Rossii [Digital Technology Alternative Dispute Resolution: Foreign Practice and Prospectsof Application in Russia]. Pravo i upravleniye. XXI vek [Law and Management. Twenty-First Century], 2018, no. 1 (46), pp. 23-31.

3. Kriminologiya: vchera, segodnya, zavtra [Criminology: Yesterday, Today, Tomorrow], 2019, no. 1 (52), pp. 18-57. URL: https://www.elibrary.ru/ contents.asp? $\mathrm{id}=38201690$ (accessed 2 Aprel 2020).

4. Kraynova N.A. Elektronnyye vesy pravosudiya: tsifrovizatsiya protsessov ili otsifrovka zadach? [Electronic Scales of Justice": Digitalization of Processes or Digitalization of Tasks?]. Kriminologiya: vchera, segodnya, zavtra [Criminology: Yesterday, Today, Tomorrow], 2019, no. 1 (52), pp. 35-38.

5. Kuzmin N.A. K voprosu o ponyatii i prirode korruptsii [On the Issue of Concept and Nature of Corruption]. Rossiyskiy sledovatel [Russian Investigator], 2009, no. 24, pp. 23-26.

6. Noskov I.Yu. Vnedreniye elektronnogo pravosudiya kak vazhneysheye napravleniye sovershenstvovaniya sudebnoy sistemy Rossiyskoy Federatsii [The Introduction of E-Justice As the Most Important Area for Improving the Judicial System of the Russian Federation]. Sovremennoye pravo [Modern Law], 2011, no. 10, pp. 120-122.

7. Otnosheniye rossiyan $\mathrm{k}$ sudebnoy sisteme (itogi vserossiyskogo oprosa). ANO «Nezavisimyy issledovatelskiy tsentr»: ofits. sayt [The Attitude of Russians to the Judicial System (the Results of the All-Russian Survey) ANO "Independent Research Center"]. URL: http://issledovatel'skij-centr.rf/ otnoshenie-rossiyan-k-sudebnoj-sisteme-itogivserossijskogo-oprosa/?ckattempt $=1$ (accessed 04 May 2018).

8. Poslaniye Prezidenta RF Federalnomu Sobraniyu ot 01.03.2018 [Message from the President of the Russian Federation to the Federal Assembly of 03/01/2018]. Rossiyskaya gazeta, 2018, 2 marta. URL: https://rg.profkiosk.ru/default?mid=30442.
9. Selivanova V.D. Elektronnoye pravosudiye kak faktor snizheniya korruptsii v organakh sudebnoy vlasti. Abubakirov F.M., Agildin V.V., Antonova E.Yu.; Basova T.B., Volkov K.A., eds. Sluzhebnyye prestupleniya: voprosy teorii i praktiki pravoprimeneniya: $s b$. materialov Mezhdunar. nauch.-prakt. konf. (17 maya 2018 g., g. Khabarovsk) [Official Crimes: Questions of Theory and Practice of Law Enforcement: Collection of Materials International. Scientific and Practical Conf. (May 17, 2018, Khabarovsk)]. Khabarovsk, Yurist Publ., 2018. 132 p.

10. SukhodolovA.P., Moscovtsev A.F., Kopylov A.V., Frolova E.E. Vvedeniye v osnovy sistemnoy antikorruptsionnoy profilaktiki [Introduction to the Basics of Systemic Anti-Corruption Prevention]. Kriminologicheskiy zhurnal Baykalskogo gosudarstvennogo universiteta ekonomiki i prava [Criminology Journal of Baikal National University of Economics and Law], 2016, vol. 10, no. 1, pp. 5-19. DOI: 10.17150/1996-7756.2016.10(1).5-19.

11. Golovanova N.A., Gravina A.A., Zaytsev O.A. [i dr.]. Ugolovno-yurisdiktsionnaya deyatelnost $v$ usloviyakh tsifrovizatsii: monografiya [Criminal Jurisdictional Activity in the Context of Digitalization: a Monograph]. Moscow, IZiSP, KONTRAKT Publ., 2019. 212 p.

12. Federalnyy zakon ot 22 dekabrya 2008 g. № 262-FZ «Ob obespechenii dostupa $\mathrm{k}$ informatsii o deyatelnosti sudov v Rossiyskoy Federatsii» (v red. ot 23.06.2016) [Federal Law of December 22, 2008 No. 262-Ф3 “On Ensuring Access to Information on the Activities of Courts in the Russian Federation" (As Amended on 06/23/2016)]. Sobraniye zakonodatelstva RF [Collection of Legislation of the Russian Federation], 2008, no. 52 (ch. 1), p. 6217.

13. Federalnyy zakon ot 14.06.2011 № 140-FZ «O vnesenii izmeneniy v statyu 14 Grazhdanskogo protsessualnogo kodeksa Rossiyskoy Federatsii i statyu 30 Ugolovno-protsessualnogo kodeksa Rossiyskoy Federatsii» [Federal Law of June 14, 2011 No. 140-FZ "On Amendments to Article 14 of the Civil Procedure Code of the Russian Federation and Article 30 of the Code of Criminal Procedure of the Russian Federation"]. Rossiyskaya gazeta [Russian Newspaper], 2011, no. 129, pp. 4-5.

14. Sharifullin R.A., Burganov R.S., Bikmiyev R.G. Elementy elektronnogo pravosudiya [Elements of Electronic Justice]. Rossiyskiy sudia [Russian Judge], 2018, no. 6, pp. 57-62. 


\section{Information About the Authors}

Olga I. Miroshnichenko, Candidate of Sciences (Jurisprudence), LL.M, Head of the Department of Theory and History of State and Law, Far Eastern Federal University, Ajax Bay, 10, 690065 Vladivostok, Russian Federation; Associate Professor, Department of Civil Law and Procedure and Private International Law, Peoples' Friendship University of Russia, Miklukho-Maklaya St., 6, 117198 Moscow, Russian Federation,olga-star.05@mail.ru, https://orcid.org/0000-0002-8248-6782

Tatyana V. Filonenko, Prosecutor, Department of State Prosecutors, Primorsky Krai Prosecutor's Office; Associate Professor, Department of Justice, Prosecutor's Supervision and Criminalistics, Far Eastern Federal University, Ajax Bay, 10, 690065 Vladivostok, Russian Federation, tanya.f-vlad@mail.ru, https://orcid.org/0000-0001-5088-2628

\section{Информация об авторах}

Ольга Игоревна Мирошниченко, кандидат юридических наук, LL.M, заведующая кафедрой теории и истории государства и права, Дальневосточный федеральный университет, пос. Аякс, 10, 690065 г. Владивосток, Российская Федерация; доцент кафедры гражданского права и процесса и международного частного права, Российский университет дружбы народов, ул. Миклухо-Маклая, 6, 117198 г. Москва, Российская Федерация, olga-star.05@mail.ru, https://orcid.org/0000-0002-8248-6782

Татьяна Викторовна Филоненко, прокурор отдела государственных обвинителей, Прокуратура Приморского края; доцент кафедры правосудия, прокурорского надзора и криминалистики, Дальневосточный федеральный университет, пос. Аякс, 10, 690065 г. Владивосток, Российская Федерация, tanya.f-vlad@mail.ru, https://orcid.org/0000-0001-5088-2628 